\title{
SIGT11 controls floral organ patterning and floral determinacy in tomato
}

\author{
Liling Yang ${ }^{1}$, Shilian Qi ${ }^{1}$, Arfa Touqeer ${ }^{1}$, Haiyang $\mathrm{Li}^{1}$, Xiaolan Zhang ${ }^{2^{*}}$, Xiaofeng $\mathrm{Liu}^{2^{*}}$ and Shuang $\mathrm{Wu}^{1^{*}}$ (D)
}

\begin{abstract}
Background: Flower development directly affects fruit production in tomato. Despite the framework mediated by $A B C$ genes have been established in Arabidopsis, the spatiotemporal precision of floral development in tomato has not been well examined.

Results: Here, we analyzed a novel tomato stamenless like flower (s/f) mutant in which the development of stamens and carpels is disturbed, with carpelloid structure formed in the third whorl and ectopic formation of floral and shoot apical meristem in the fourth whorl. Using bulked segregant analysis (BSA), we assigned the causal mutation to the gene Solanum lycopersicum GT11 (SIGT11) that encodes a transcription factor belonging to Trihelix gene family. SIGT11 is expressed in the early stages of the flower and the expression becomes more specific to the primordium position corresponding to stamens and carpels in later stages of the floral development. Further RNAi silencing of SIGT11 verifies the defective phenotypes of the s/f mutant. The carpelloid stamen in s/f mutant indicates that SIGT11 is required for B-function activity in the third whorl. The failed termination of floral meristem and the occurrence of floral reversion in sIf indicate that part of the C-function requires SIGT11 activity in the fourth whorl. Furthermore, we find that at higher temperature, the defects of s/f mutant are substantially enhanced, with petals transformed into sepals, all stamens disappeared, and the frequency of ectopic shoot/floral meristem in fourth whorl increased, indicating that SIGT11 functions in the development of the three inner floral whorls. Consistent with the observed phenotypes, it was found that B, C and an E-type MADS-box genes were in part down regulated in slf mutants.
\end{abstract}

Conclusions: Together with the spatiotemporal expression pattern, we suggest that S/GT11 functions in floral organ patterning and maintenance of floral determinacy in tomato.

Keywords: Tomato, SIGT11, Floral reversion, Floral organ identity, Floral determinacy

\footnotetext{
*Correspondence: zhxiaolan@cau.edu.cn; liuxiaofeng@cau.edu.cn; wus@fafu.edu.cn

${ }^{2}$ State Key Laboratories of Agrobiotechnology, Beijing Key Laboratory of Growth and Developmental Regulation for Protected Vegetable Crops, MOE Joint Laboratory for International Cooperation in Crop Molecular Breeding, China Agricultural University, Beijing, China

${ }^{1}$ College of Horticulture, FAFU-UCR Joint Center and Fujian Provincial Key Laboratory of Haixia Applied Plant Systems Biology, Fujian Agriculture and Forestry University, Fuzhou, China
}

(C) The Author(s). 2020 Open Access This article is licensed under a Creative Commons Attribution 4.0 International License, which permits use, sharing, adaptation, distribution and reproduction in any medium or format, as long as you give appropriate credit to the original author(s) and the source, provide a link to the Creative Commons licence, and indicate if changes were made. The images or other third party material in this article are included in the article's Creative Commons licence, unless indicated otherwise in a credit line to the material. If material is not included in the article's Creative Commons licence and your intended use is not permitted by statutory regulation or exceeds the permitted use, you will need to obtain permission directly from the copyright holder. To view a copy of this licence, visit http://creativecommons.org/licenses/by/4.0/. The Creative Commons Public Domain Dedication waiver (http://creativecommons.org/publicdomain/zero/1.0/) applies to the data made available in this article, unless otherwise stated in a credit line to the data. 


\section{Background}

Flowers of angiosperms are the reproductive organs playing an important role in reproduction. A typical eudicot flower, such as Arabidopsis and tomato, consists of four different organs arranged in four whorls at the tip of floral shoot. Based on genetics studies on model plants including Arabidopsis [1-3], Antirrhinum majus [1] and Petunia hybrid [4], an elegant model involving $\mathrm{ABCDE}$ class genes, has been proposed to explain the organ patterning in flower. In Arabidopsis, A class genes APETALA1 (AP1) and APETALA2 (AP2) are involved in the development of sepals and petals. $B$ class genes APETALA3 (AP3) and PISTILLATA (PI) can form protein complexes with $C$ class gene AGAMOUS $(A G)$ and E class genes SEPALLATAs (SEPS) to promote stamens development. The carpels formation is regulated by both $\mathrm{C}$ class genes $A G s$ and $\mathrm{E}$ class genes SEPs. The interference of $\mathrm{ABCDE}$ genes leads to confusion in the identity of floral organs [3,5]. Compared with Arabidopsis, tomato genome has more homologous $\mathrm{ABCDE}$ genes. Tomato possesses four $\mathrm{B}$ class homologous genes, two DEF lineage genes-Tomato APETALA3 (TAP3) and Tomato MADS-box 6 (TM6), two GLO genes-Solanum lycopersicum GLOBOSA (TPIB, SlGLO1) and Tomato PISTILLA TA (TPI, SlGLO2) [6, 7]. In tomato, there are two C class homologous genes (TOMATO AGAMOUS 1 (TAG1) and TOMATO AGAMOUS-LIKE 1 (TAGL1)) [8, 9] and six E class homologous genes (Tomato MADSbox 5 (TM5), TM29, JOINTLESS-2 (J2), ENHANCER-ofJOINTLESS2 (EJ2), RIPENING INHIBITOR (RIN) and Solyc04g005320) [10]. Although the ABC genes clearly have similar functions between Arabidopsis and tomato, they may have separate functions independent of each other.

The development of stamens and carpels has drawn particular attention, as the regulation of these two floral parts is important for crop breeding. In Arabidopsis, mutations in the B-class genes APETALA3 (AP3) or PISTIL $L A T A(P I)$ promote the conversions of petals into sepals and stamens into carpels [1]. Similarly, the tomato stamenless mutant was identified to have mutations in $\mathrm{B}$ class gene TAP3 $[11,12]$. In the mutant, stamens are completely transformed into carpels which are fused with the carpels in the fourth whorl to form a unique gynoecium, and petals are partially transformed into sepals $[11,12]$. The silencing of another B class gene TM6 also produced similar phenotypes $[6,13]$. Mutants of the B-class genes DEFICIENS (def) and GLOBOSA (glo) triggered the same homeotic transformations in Antirrhinum [14]. The rice stamenless 1(sl1) mutant exhibits homeotic conversions of lodicules and stamens to palea/ lemma like organs and carpels, which resembles the mutant of B class gene SPW1 [15]. Another type of homeotic transformation has also been reported in these species. In Arabidopsis, the mutant of the C-class gene $A G$ showed that the stamens and carpels were transformed into petals and sepals [1]. These phenotypes are very similar to the tag1 mutant in tomato [8] and agamous-like flower (aglf) mutant in Medicago truncatula [16].

The initiation and termination of floral meristem are precisely controlled to ensure the successful development of flowers, in which a set of transcription factors are spatiotemporally coordinated [17]. In Arabidopsis, the activity of floral meristem (FM) is maintained through the WUSCHEL-CLAVATA (WUS-CLV) signaling pathway, which plays a key role in maintaining undifferentiated cell populations in the meristem $[18,19]$. In addition, the $a g-2$ mutant in Arabidopsis produce flowers without stamens and carpels and form indeterminate flowers with reiterating sepals and petals, suggesting AG is very important for floral meristem determinacy [20]. The LEAFY (LFY) gene together with WUSCHEL (WUS) activates AGAMOUS (AG) at floral stage $3[21,22]$. While in later stages of the floral development (starting from stage 6), induction of KNUCKLES $(K N U)$ by $A G$ is crucial for the timely termination of FM [23]. In addition, high $A G$ level indirectly regulates WUS activity to ensure the proper termination of meristematic activity in the FM, in which a set of regulators including trithorax group protein ULTRAPETALA1 (ULT1), bZIP transcription factor PERIANTHIA (PAN), and other factors such as REBELOTE (RBL) and SQUINT (SQN) are involved [24-28]. The tetramerization of SEPALLATA3 (SEP3) and AG is essential for AG function that activates CRABS CLAW (CRC) and KNU during floral determinacy. In addition, these regulatory networks also interplay with plant hormones during the floral development. It was found that AUXIN RESPONSE FACTOR 3 (ARF3) is transcriptionally regulated by AG and APET ALA2 (AP2) in developing flowers, which represses cytokinin activity to inhibit WUS expression [29]. The mechanisms regulating floral development seem to be conserved among species. It has been found that KNU interacts with MINI ZINC FINGER (MIF) to regulate WUS expression and this mechanism is conservative between Arabidopsis and tomato [30].

Floral reversion is an unusual process in which the committed floral development is reverted back to vegetative growth, resulting in outgrowth of leaves or inflorescence structures from the first flower [31]. This phenomenon is usually related to varied environmental conditions, such as temperature and photoperiod [31]. For example, the floral reversion was observed in lfy- 6 and ag-1 mutants of Arabidopsis grown in short-day conditions [32]. Floral reversion was also observed in natural allopolyploid Arabidopsis suecica, in which abnormal expression of floral genes, including $A G L 24$, APELATA1 (AP1), SHORT VEGETATIVE STAGE (SVP) 
and SUPPRESSOR OF CONSTANS1 (SOC1) were detected [33, 34]. Unlike in Arabidopsis, LEAFY (LFY), TERMINAL FLOWER1 (TFL1) and AG in Impatiens balsamina seemed not to be involved in terminal flowering and floral determinacy [35]. In Petunia hybrida, cosuppression of FLORAL BINDING PROTEIN1 (FBP2), a homolog of Arabidopsis SEPALLATA-like gene, led to new inflorescences growing from axils of carpels [36]. In tomato, the down-regulated of TM29, a homolog of Arabidopsis SEPALLATA gene, also resulted in ectopic leafy stems and flowers formed in fruits [37].

In this study, we identified a tomato recessive mutant with the mutation in the gene Solyc03g006900 which is named Solanum lycopersicum GT1 (SlGT11) based on the previous nomenclature and encodes a transcription factor belonging to Trihelix gene family [38]. Recently, a mutant of SlGT11 ortholog in Medicago truncatula has been reported to control the $\mathrm{C}$-function gene expression and it was named AGAMOUS-LIKE FLOWER (AGLF) [16]. In aglf mutant, the stamens and carpels in the inner whorl are replaced by petals and sepals respectively, resembling the floral phenotype of ag-1 mutant in Arabidopsis $[16,20,39]$. We found that the loss-function of SlGT11 resulted in sepaloid petal at high temperature in the second whorl, carplloid stamen in the third whorl, and ectopic formation of stem-, leaf- and flower-like structures in the fourth whorl. Together with the result that $\mathrm{B}, \mathrm{C}$ and an E-type MADS-box genes were downregulated in slf mutants, we concluded that SlGT11 has important functions in the development of the three inner floral whorls. Furthermore, spatiotemporal expression analysis showed that SlGT11 was expressed throughout the flower in the early stages and its expression became more specific to the primordium position of stamens and carpels in later stages of the floral development. Together our results suggest that SlGT11 functions in floral organ patterning and maintenance of floral determinacy in tomato.

\section{Results}

\section{Identification of the slf mutant}

In order to study the mechanism regulating floral organ identity in tomato, we screened tomato EMS-mutant library [40] and identified a mutant (TOMJPG2637-1) with identity defects in stamens and pistils, while the identity and number of sepals and petals were unchanged compared with wild type (WT) (Fig. 1a-c, e, g). In the mutant, stamens showed severely carpelloid in the third whorl (Fig. 1a). From the longitudinal sections, we verified that the pistil-like structures were formed in the third whorl (Fig. 1a, b). Only a few flowers ( 22.95\%) have stamen-like structure remaining in the third whorl of the mutant based on the transverse sections of flowers (Fig. 1b, d). The carpelloid stamens of the mutant developed into irregular fruits with more locules and the vestigial stamen structures were later formed radial cracks on the fruit surface (Fig. 1c). As this phenotype is similar to previously reported stamenless mutant [11, 12], we thus named the mutant stamenless like flower $(s l f)$.

Besides, our histological analyses showed that new shoot/floral meristems instead of carpel primordium formed in the fourth whorl of the mutant (Fig. 1. g). The ectopic shoot/floral meristem in the slf mutant produced ectopic aberrant foliage and flowers in the fourth whorl, indicating that the normal floral determinacy was lost (Fig. 1. g). As a result, the carpelloid stamen in slf mutant developed into the parthenocarpic fruit without seeds (Fig. 1c, d, Fig. S1c, d). Interestingly, in the carpallike structure, the ovule development seemed normal in slf mutant. Therefore, we attempted to use WT pollen grains for the cross-pollination in slf mutant, and only small amount of seeds were obtained. This result may be due to the abnormal pistil-like structures that hindered the pollen-ovule process (Fig. S1e, g). All these results indicated that the slf mutant was almost sterile.

\section{SIGT11 gene encodes a regulator involved in floral organ identity}

To identify the causal gene in slf mutant, we first conducted a genetic analysis by crossing the mutant to the WT. In the F2 segregated population, we found 92 progenies resembling the WT and 28 progenies with slf phenotypes, which were close to the 3:1 Mendelian segregation rule, indicating that the phenotypes in slf were caused by a recessive mutation at a single locus. Through bulked segregant analysis sequencing (BSA-Seq), we identified a signal peak on chromosome 3 (Fig. 2a). Further SNP analysis assigned the causal mutation to the gene Solyc03g006900 which encodes a nucleuslocalized Trihelix transcription factor named SIGT11 previously [38], containing a putative GT1 DNAbinding domain and a PKc kinase domain (Fig. S3). The A to $\mathrm{T}$ substitution at the $2195 \mathrm{bp}$ position identified forms the termination codon TAG and mRNA level of the SlGT11 gene in the mutant was significantly decreased (Fig. 2b, f). Further sequencing analyses verified that the base substitution occurred in all 28 F2 progenies with slf phenotypes (Fig. 2c). Subcellular localization in tobacco leaves showed that SIGT11-GFP was located in the nucleus, consistent with the presence of DNA-binding domain (Fig. 2d).

To further verify the SlGT11 function, we transformed WT tomato with an RNA interference (RNAi) plasmid targeting the C-terminus of the SlGT11. The phenotypes of 5 independent transgenic RNAi lines were consistent with the slf mutant. qRT-PCR verified the significant reduced expression of SlGT11 in RNAi lines (Fig. 2f). The 


\section{a}
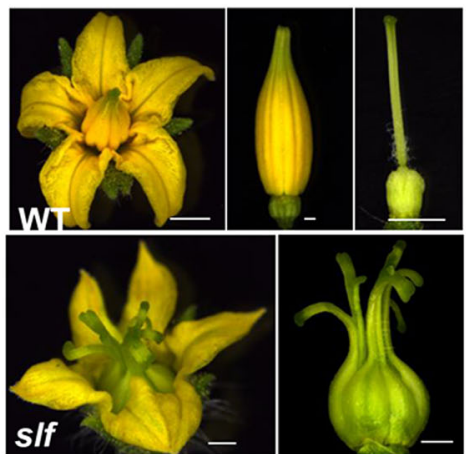

b
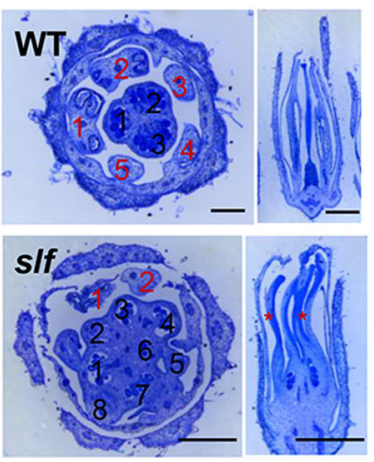

C
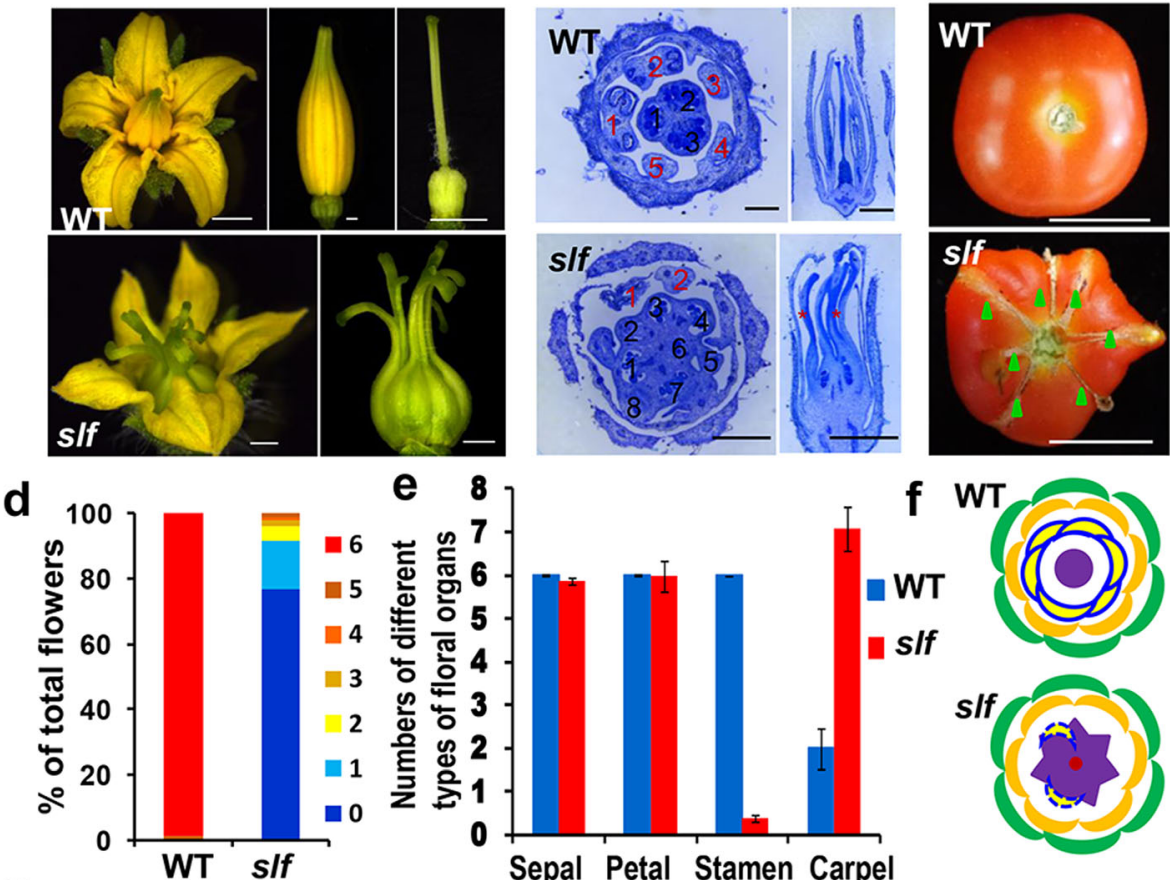

e 8

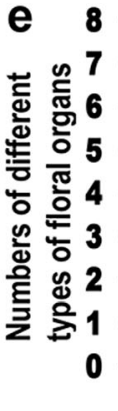

0
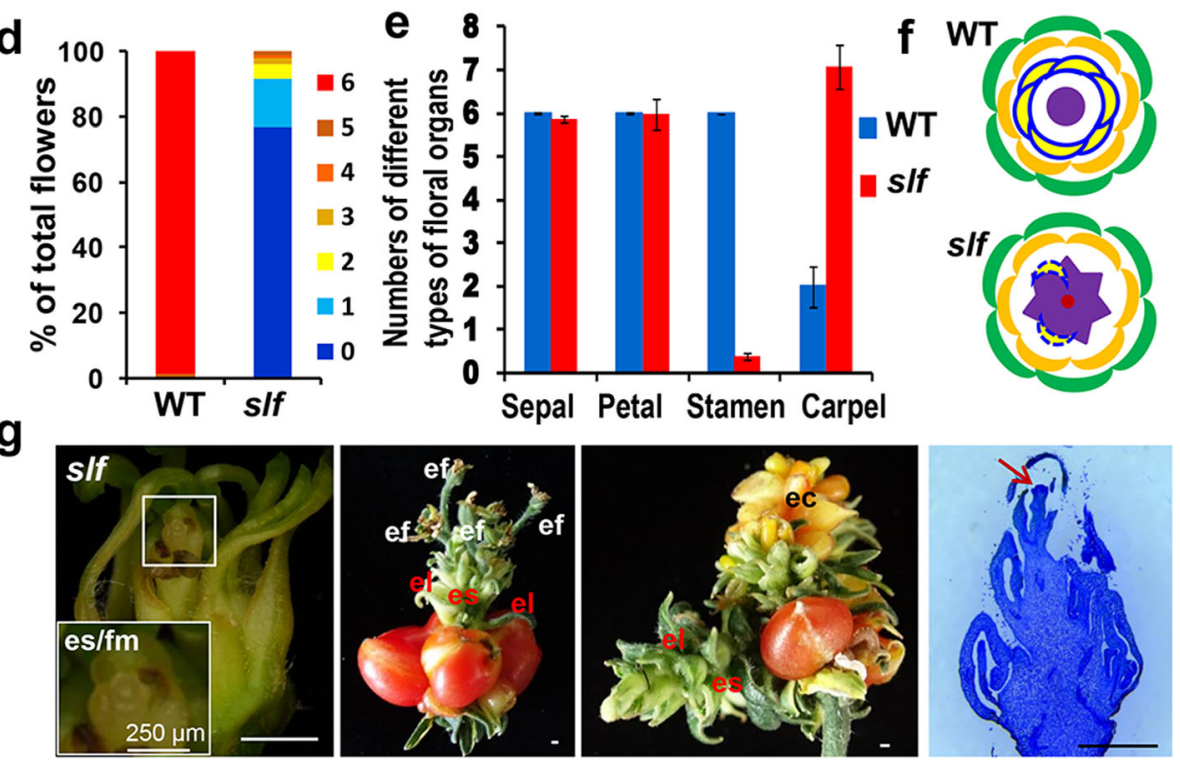

Fig. 1 The slf mutant shows deficiencies in floral organ identity. a The floral phenotypes of WT and slf. $\mathbf{b}$ Transverse and longitudinal sections (stained with toluidine blue) of WT and slf flowers at developmental stage 18. Red and black numbers indicate the number of stamens and locules, respectively; red asterisks indicate the conversion of the stamens into pistils in the third whorl. c The fruit of WT and slf. Green triangles indicate rough radial lines caused by the formation of vestigial stamen-like structures. $\mathbf{d}$ Percentage of the flowers with 0-6 stamens in WT and slf. e Quantification of sepals, petals, stamens and carpels in WT and slf. The vestigial stamen-like structure in slf is counted as the stamen; the carpelloid stamen in slf is counted as the carpel. The data represent means \pm SD $(n=296)$. $\mathbf{f}$ A schematic diagram of the floral organs in WT and slf. The WT flower consists of four whorls: sepal (green), petal (orange), stamen (yellow and blue solid line), and carpel (purple). The slf flower consists of sepals (green) in the 1st whorl, petals (orange) in the 2nd whorl, carpelloid stamens (purple) with or without stunted stamens (yellow and blue dotted line) in the 3rd whorl, and ectopic shoot/floral meristem in the 4th whorl (red circular). $\mathbf{g}$ Ectopic shoot/floral meristems emerge in the flower, and ectopic shoots produce flowers and leaf-like structures in the fruit, longitudinal sections of the s/f flowers show ectopic meristem stained with toluidine blue at the floral developmental stage 14. es/fm: ectopic shoot/floral meristem; es: ectopic stem; ef: ectopic flower; el: ectopic leaf; ec: ectopic carpel. Scale bars: $(\mathbf{a}, \mathbf{b}, \mathbf{g}) 1 \mathrm{~mm}$

observed phenotypes including carpelloid stamens in the third whorl and new meristem formation from the fourth whorl in RNAi lines (\#1 and \#6) indicated that SlGT11 was the gene causing the developmental defects of stamens and carpels in slf (Fig. 2e). In addition, abnormal fruits were also found in transgenic lines \#1 and \#6, indicating that SlGT11 plays an important role in regulating the floral identity and floral meristem termination (Fig. 2g).
Phylogenetic analysis showed that all the SIGT11 homologous genes in solanaceae were grouped into the same cluster, while Arabidopsis homologous gene At5g51800 belonged to a less related cluster (Fig. S2). Consistent with this phylogenetic distance, At5g51800 mutation does not cause the similar floral phenotype, indicating the function of this gene is not completely conserved among different species. The comparative analysis of the amino acid sequence of SIGT11 in solanaceae showed 

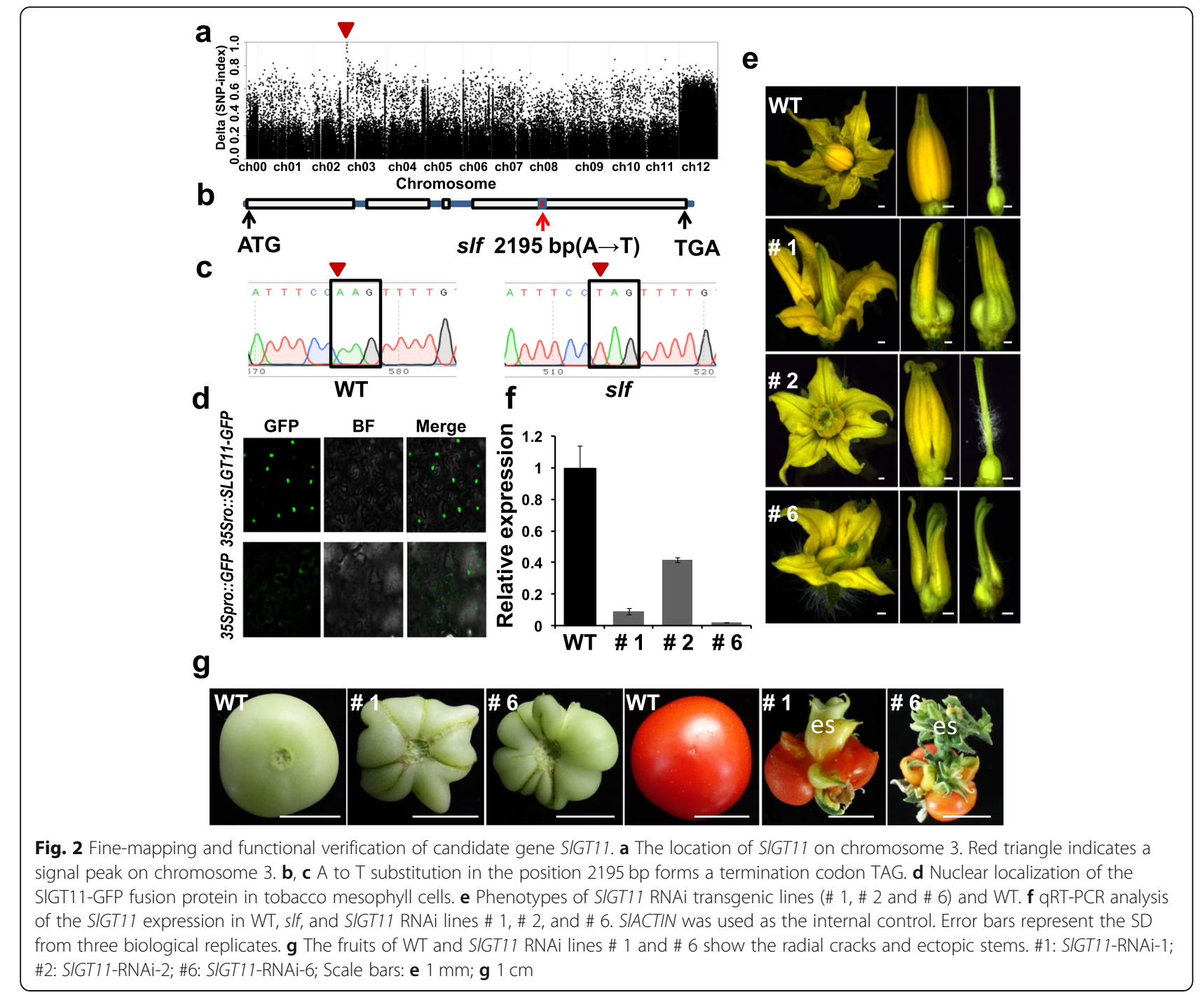

that the N-terminal GT1 domain and the C-terminal PKc kinase domain are highly conserved (Fig. S3).

\section{Spatial and temporal expression pattern of SIGT11 in tomato}

To examine the expression pattern of SlGT11, we performed qRT-PCR in different tomato tissues including roots, hypocotyls, cotyledons, stems, leaves, flowers and fruits. The expression of SlGT11 was highly enriched in the flowers (Fig. 3a). Then RNA was extracted from different parts of flowers at anthesis for qRT-PCR and we found that SlGT11 was predominantly expressed in stamens, indicating that SlGT11 could be important for stamen development (Fig. 3b). Furthermore, we analyzed the temporal expression trend of SlGT11 during the floral development. qRT-PCR showed that SlGT11 expression was time-specific, with high expression levels from 6 days to 2 days before flowering (at stage12-18) (Fig. 3c).
Furthermore, we constructed a GUS reporter driven by SlGT11 promoter and transformed it into WT tomato (Fig. 3d). GUS staining showed that SlGT11 was expressed throughout the early stages of flowers and the expression became more specific to the stamen and carpel in later stages (Fig. 3e). The expression pattern of SlGT11 in inner two whorls of flower implies that it is probably involved in the regulation of tomato stamen and carpel development.

\section{Stamen defects occur at the early stage}

To investigate how SIGT11 affects stamens and carpels at different floral developmental stages [41], we used scanning electron microscopy (SEM) to visualize the floral development in WT, slf and SlGT11 RNAi line 6 (Fig. 4a-o). The early stages (before the stage 3 when sepal primordia and petal primordia were initiated) of floral development in slf and SlGT11 RNAi line 6 appeared to be similar to that of the WT (Fig. 4a-f). At 

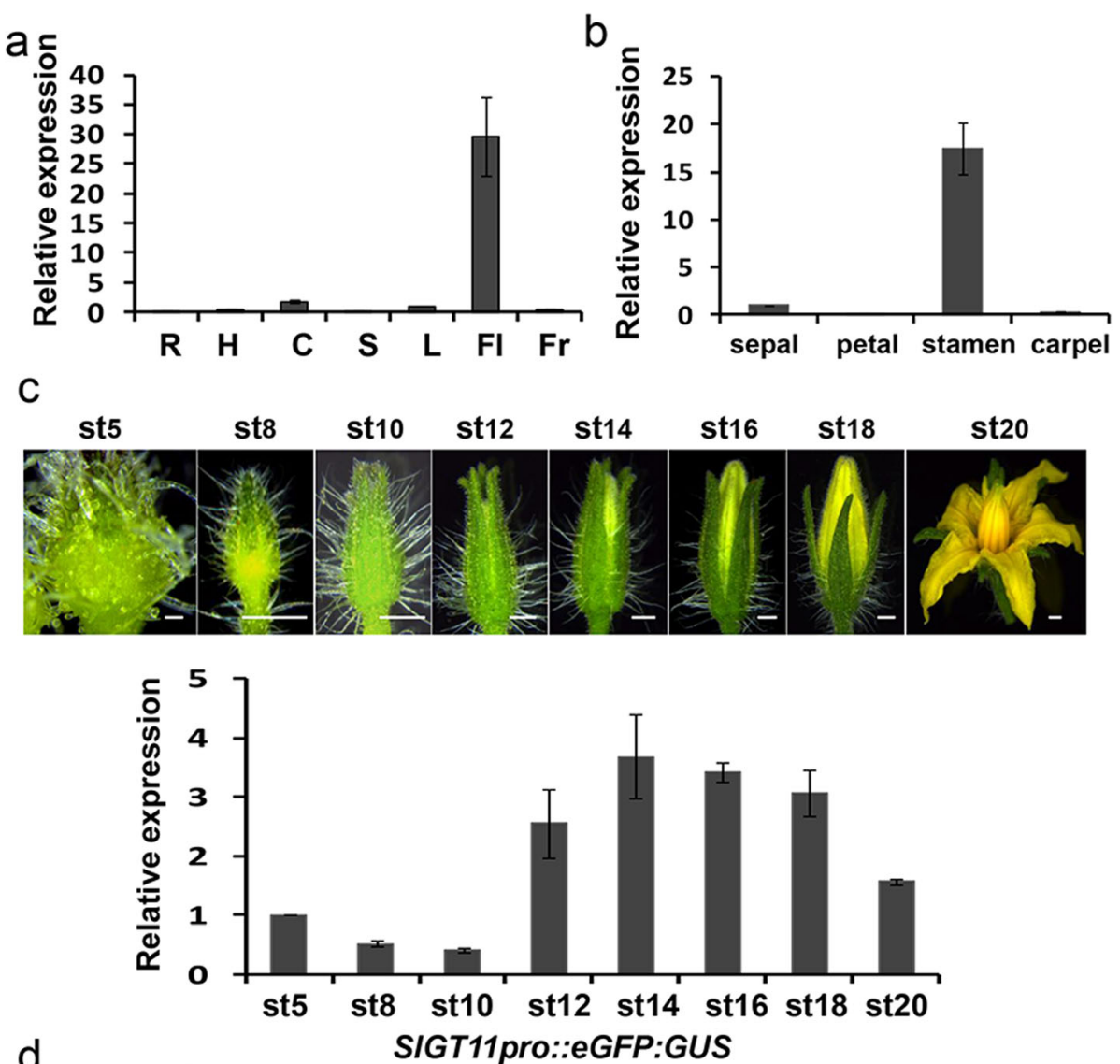

d
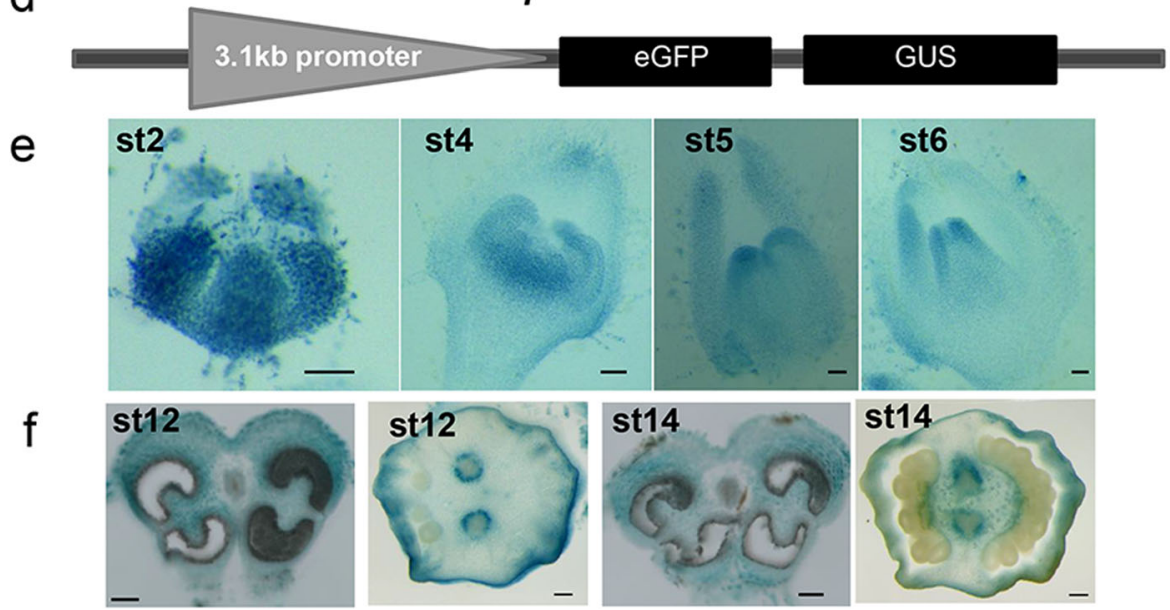

Fig. 3 Spatiotemporal expression pattern of SIGT11. a qRT-PCR analysis of SIGT11 in different tissues. $\mathbf{b}$ qRT-PCR analysis of SIGT11 in different floral organs. c qRT-PCR analysis of SIGT11 at different developmental stages of flower. SIACTIN was used as the internal control. Error bars represent the SD from three biological replicates. $\mathbf{d}$ The diagram of the GUS reporter driven by SIGT11 promoter. e GUS activity was detected throughout the development of the flowers. GUS staining of SIGT11 promoter was visible in sepals, petals, stamens and carpel primordial, with the strong expression in the stamens and vascular bundles in the ovary. $\mathbf{f}$ Transverse sections of the stamen and ovary at the stages 12 and 14 showing the GUS activity in anthers and vascular bundles. R: root; H: hypocotyl; C: cotyledon; S: stem; L: leaf; Fl: flower; Fr: fruit; st: stage. Scale bars: (c and e) $1 \mathrm{~mm}$; (f) $100 \mu \mathrm{m}$

stage 5, the differences between WT and slf or SlGT11 RNAi line 6 became more prominent. In the WT, six stamen primordia and one carpel primordium with four locules were initiated in the third and fourth whorl respectively (Fig. 4g). In contrast, the third and fourth floral organ primordia in the slf and SlGT11 RNAi line 6 were initiated in disorder (Fig. $4 \mathrm{~h}, \mathrm{j}$ ). The defective floral organ identity became more severe in slf and SlGT11 


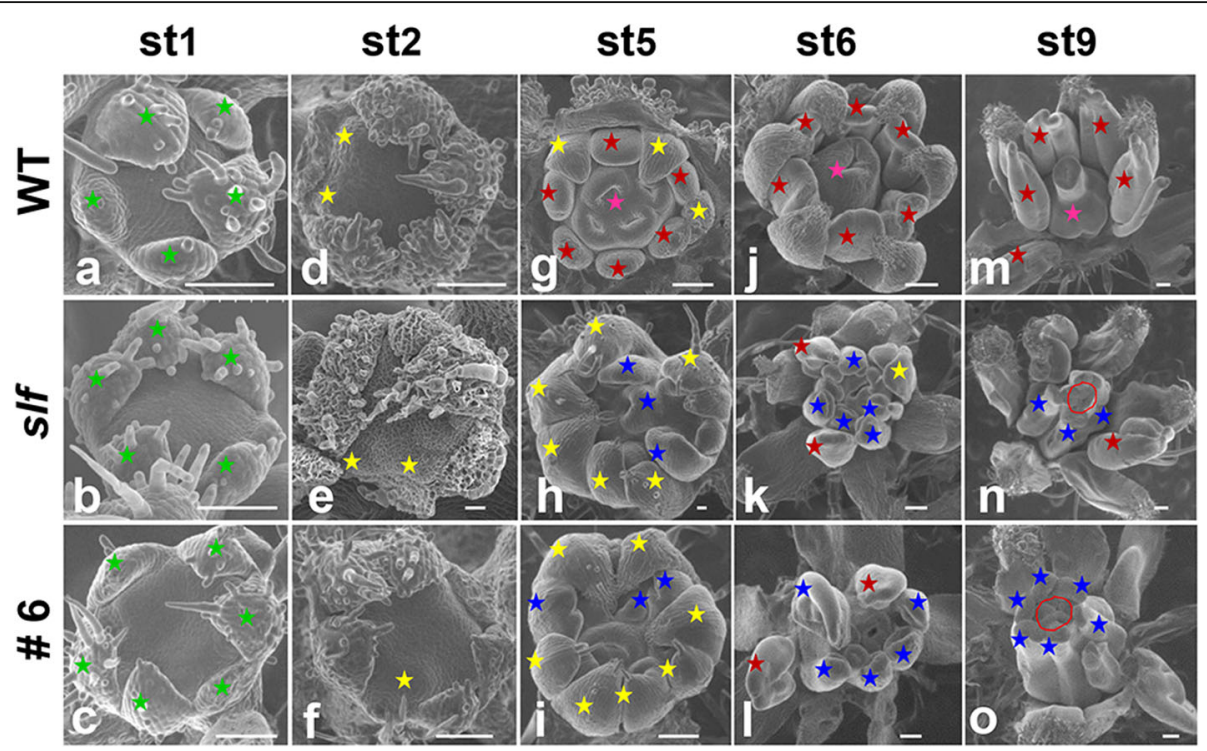

Fig. 4 SEM micrographs of floral organs at early developmental stages in WT, slf and SIGT11RNAi line 6. SEM images of the floral meristem in WT $(\mathbf{a}, \mathbf{d}, \mathbf{g}, \mathbf{j}$ and $\mathbf{m})$, slf ( $\mathbf{b}, \mathbf{e}, \mathbf{h}, \mathbf{k}$ and $\mathbf{n})$ and SIGT17-RNAi-6 ( $\mathbf{c}, \mathbf{f}, \mathbf{i}, \mathbf{I}$ and $\mathbf{o})$. Green stars indicate sepal primordia; yellow stars indicate petal primordia; red stars indicate stamen primordia; pink stars indicate carpel primordia; bule stars indicate carpelloid stamens; red lines circle the abnormal carpel primordial with ectopic meristems; Scale bars: $100 \mu \mathrm{m}$; st: stage

RNAi line 6 at stages 6 and 9 (Fig. 4j, m). In the mutant, most stamens were transformed into carpel-like structures, and some ectopic meristems were produced in the central area of the flower (Fig. 4k, l, n and o). Combined with the spatiotemporal expression, we concluded that SlGT11 plays an essential role in the early development of floral organs.

\section{Expression of floral development genes in slf mutant}

Since the defects of stamens and carpels occurred at the early stages, we compared the expression of BCE genes that were previously reported to affect stamen and carpel identity in the floral buds at stage 1-6 between WT and slf [41]. Consistent with the phenotypes, the $\mathrm{BCE}$ genes showed the distinct expression pattern between WT and slf mutant. Class B genes TAP3, TPI and $T P I B$, class $\mathrm{C}$ genes TAG1, TAGL1 and class $\mathrm{E}$ gene $T M 29$, were all significantly down-regulated in slf. However, the expression level of the B-class gene TM6 and E class gene TM5 were not significantly affected in slf during the floral development (Fig. 5a).

We next analyzed the expression levels of some regulators involved in floral meristem identity and floral meristem termination. Since the ectopic floral meristem was repeatedly emerged in the later stages of floral development (Fig. 1g), we chose a set of essential genes for floral development including SlWUS, SlKNU, SlCLV3, SlCLV1, SlCLV2, FALSIFLORA (FA), SIULT1-like and SIRBL-like for transcriptional analysis at the later floral stage (stage 20). FA and SlWUS were up-regulated in slf, while SIKNU, SlCLV3, SlCLV1 and SlULT1-like appeared to be down- regulated in slf flowers (Fig. 5b, c). These results were consistent with the floral meristem termination defects in slf mutant.

\section{High temperature inhibits the expression of SIGT11 and TM29}

During the cultivation in the greenhouse where the temperature in summer was higher than the standard, we found that the phenotypes of slf became more severe, with stamens hardly visible and the defective flowers with ectopic floral meristem dramatically increased. As the temperature was reported previously to play a role in the floral development [42], we tested whether the SlGT11 function is also affected by temperature. To that end, we germinated the WT and slf mutant seeds at $25^{\circ} \mathrm{C}$ for 4 weeks, and grew them in a heated incubator $\left(37^{\circ} \mathrm{C}\right.$ daytime/ $28^{\circ} \mathrm{C}$ at night) for 20 days. The flowers produced by the slf mutant grown at the higher temperature had more carpelloid structures and no stamen-like structures in the third whorl was visible (Fig. 6d). In addition, the petals seemed to partially acquire sepals identity by forming greenish petals with sepal structure (Fig. 6f). Furthermore, we found shoot/floral meristems were produced at the center of the mature flowers (Fig. 6d). Despite the carpelloid stamens and ectopic shoot/ floral meristems were also produced in slf flowers at lower temperature $\left(25^{\circ} \mathrm{C}\right.$ daytime $/ 22^{\circ} \mathrm{C}$ night $)$, their occurrence frequency became significantly higher at higher temperature. 


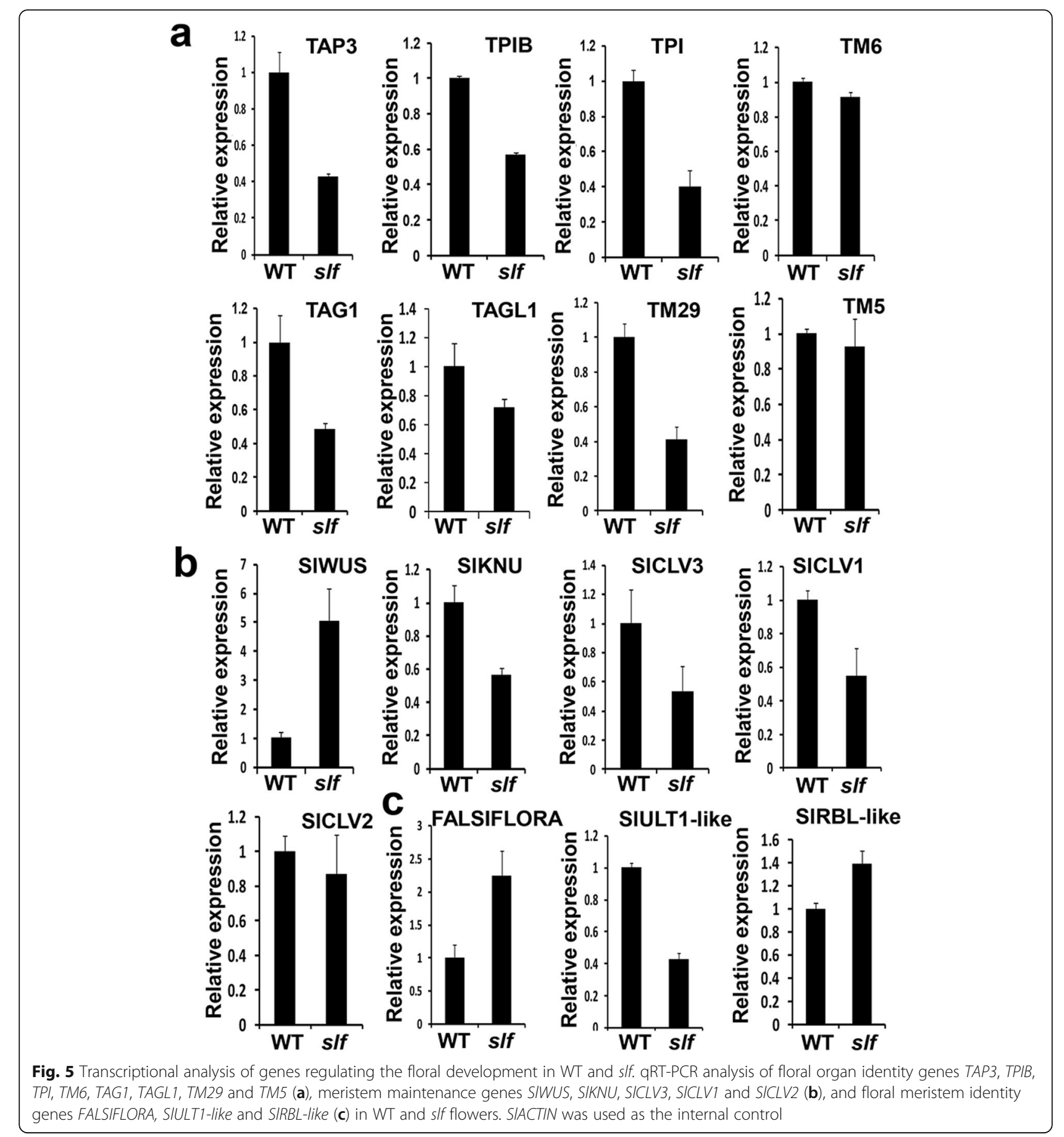

To further dissect the influence of the higher temperature on SlGT11, we performed qRT-PCR to analyze potential transcriptional change. The floral buds at early stages of WT and slf mutant grown at higher temperature were collected for RNA extraction and qRT-PCR. Our results showed that SlGT11 expression was inhibited by the higher temperature (Fig. 6g). We then examined the expression levels of BCE genes at $3 \mathrm{~h}, 7 \mathrm{~h}$ and $24 \mathrm{~h}$ after the high temperature treatment. Our results showed that E class gene TM29 was further significantly down-regulated by high temperature in slf mutant (Fig. 6h, i). Yeast-one-hybrid assay failed to detect the direct binding of SlGT11 to the TM29 promoter region. All results (Fig. 5, Fig. 6 g-i) indicate that SIGT11 indirectly activates TM29 transcription, and the high temperature further represses the transcription of SlGT11 and TM29 both in WT and slf. 

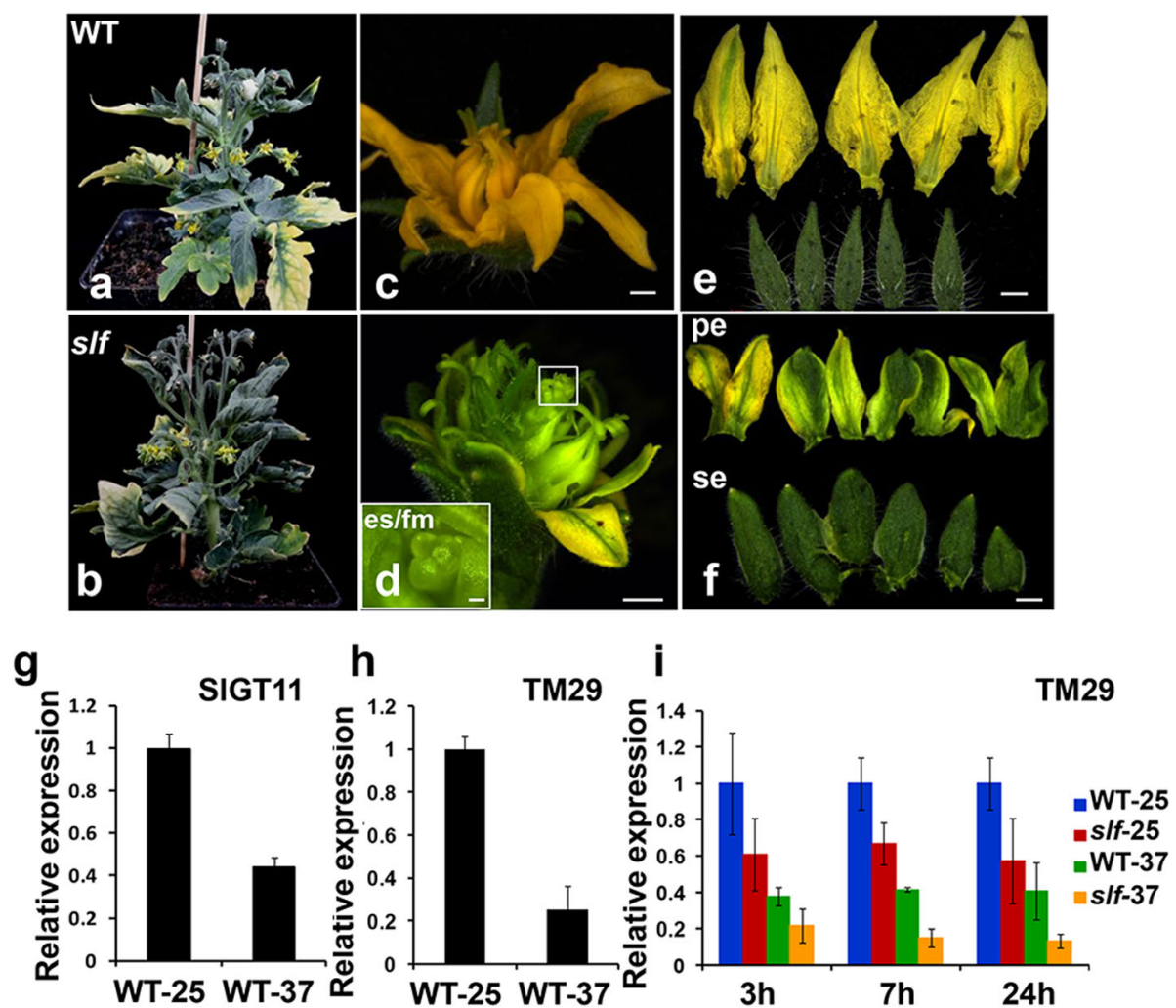

Fig. 6 High temperature impacts on the floral identity in WT and slf mutant. a The flowers of WT treated with high temperature caused stamen separation (c), and normal sepals and petals (e). b The flowers of the slf mutant treated with high temperature show greenish petals (f) and ectopic shoot/floral meristems (es/fm) in the fourth floral whorl organs (d). $\mathbf{g}$ qRT-PCR analysis of S/GT1 1in WT floral buds treated with $25^{\circ} \mathrm{C}$ (WT25) and $37^{\circ} \mathrm{C}$ (WT-37). $\mathbf{h}$ qRT-PCR analysis of TM29 in WT floral buds treated with $25^{\circ} \mathrm{C}$ (WT-25) and $37^{\circ} \mathrm{C}$ (WT-37). (I) qRT-PCR analysis of TM29 in WT and slf mutant floral buds treated with $25^{\circ} \mathrm{C}$ (WT-25 and slf-25) and $37^{\circ} \mathrm{C}$ (WT-37 and slf-25) after $3 \mathrm{~h}, 7 \mathrm{~h}$ and $24 \mathrm{~h}$. SIACTIN was used as the internal control. Error bars represent the SD from three biological replicates. es/fm, ectopic shhot/floral meristem; se, sepal; pe, petal; Scale bars: (c) $1 \mathrm{~cm}$; (d) left $250 \mu \mathrm{m}$, right $1 \mathrm{~mm}$; (e) and (f): $1 \mathrm{~mm}$

\section{Discussion}

The classic ABC model was previously established in the model plants Arabidopsis and Antirrhinum majus [1]. In A-class mutants, flowers have carpels-stamens-stamenscarpels (from the outermost to the innermost whorl), while B-class mutants have sepals-sepals-carpels-carpels flowers and C-class mutants have sepals-petals-petals-sepals flowers. E-class mutants have the flower with all organs resembling sepals $[1,43]$. In tomato, the functions of $\mathrm{B} / \mathrm{C} / \mathrm{E}$ class genes seem to be more complicated than those in Arabidopsis and Antirrhinum. There are four homologous class B genes in tomato: TAP3, TM6, TPI and TPIB. Despite similar phenotypes were observed when TAP3 and TPIB were mutated, mutations in TM6 or TPI only resulted in the transformation of stamens into carpels without affecting petals and carpels $[6,7,13$, 44, 45]. Two tomato C class genes TAG1 and TAGL1 have redundant and divergent functions in the floral development [9]. The transgenic plants expressing TAG1 antisense RNA showed homeotic conversion of third whorl stamens into petaloid organs and the emergence of indeterminate floral meristems in the fourth whorl [8]. However, TAGL1 mainly specifies stamens and carpels development in flowers and controls fruit development and ripening [46]. E class gene TM29 expression was down-regulated by the co-suppression produced aberrant flowers with morphogenetic alterations in the organs of the inner three whorls. In these three whorls, petals and stamens were partially conversed to a sepalloid structure, and ectopic shoots with leaves and secondary flowers emerged from the fruit [37]. In this study, we identified the recessive mutant of SlGT11 gene whose phenotypes resemble some previously characterized mutants with dysfunctional $\mathrm{B} / \mathrm{C} / \mathrm{E}$ class genes. The carpelloid stamen in slf mutants indicates that SIGT11 is required for the function of $B$ type genes in the third whorl. The failed termination of floral meristem and the occurrence of floral reversion in slf indicate that the function of C type genes partially requires SlGT11 activity in the fourth whorl. Furthermore, we found that the defects in slf were substantially enhanced at higher temperature, with petals transformed into sepals, and 
the frequency of ectopic shoot/floral meristem in fourth whorl increased. This suggests that SlGT11 is critical in the development of the three inner floral whorls.

SlGT11 is expressed extensively in the early stage of floral development, but its expression gradually became concentrated in the stamens and the vascular bundles of the ovary. We speculate that SlGT11 plays the roles in the initiation of each whorl of floral organs, especially the initiation of stamens. It has been reported that the expression of BCE genes which affects stamens development overlaps with SlGT11 expression domain. Class B genes including TAP3, TM6 and TPI were all previously shown to have expression in the stamen position $[6,7]$. The C gene TAG1 is also mainly expressed in the stamens and carpels during the floral development in tomato [8]. Compared with the class $\mathrm{B}$ and $\mathrm{C}$ genes, the expression of TM29 at early stage was more extensive, including vascular bundles. But during the later stage of the floral development, TM29 expression is mainly concentrated in stamens and carpels, which overlaps with the expression domain of SlGT11 [37]. In addition, the SlGT11 gene is also expresses in vascular bundles, which could be the origin of the abnormal stem. Compared with the WT, the expression of TAP3, TPI, TPIB and TM29 in slf was all down-regulated, suggesting SlGT11 could regulate the $\mathrm{BCE}$ gene expression to promote the stamens development. Therefore, SlGT11 could be one of regulators in addition to the $\mathrm{ABC}$ model genes that regulate floral organ development.

Floral development is strictly controlled by complex regulatory networks to ensure the successful reproduction of plants. Under natural conditions, the transition from vegetative to reproductive growth is irreversible so the correct tissue patterning can be achieved during the floral development [31]. slf mutant has a reversion of floral development to vegetative organs, indicating that meristem termination in flowers becomes defective. As evidenced by a number of previously characterized mutants including TAP3, TPIB and TM6, this reversion phenotype is not necessarily associated with the defects of fused stamens and carpels though [6, 7]. In Arabidopsis, the carpels of a weak allele $a g-4$ are partially transformed into sepals while the stamens and carpels of a strong allele $a g-6$ are completely transformed into petals and sepals [5, 20,47]. Despite new flowers are formed in the whorl four of ag-2 flowers, no leaves can be seen, indicating that this defect only represents the aberrant termination of flower meristem [1]. But grown in short day, ag-1 mutants displayed the reversion of floral meristem back to vegetative development in Arabidopsis. Similar phenotype was also reported in Arabidopsis mutant $l f y-6$ [32]. The direct homologous gene of $A G$ in tomato is TAG1. In line with the conserved function of $A G$, tag1 showed homeotic conversion of the third whorl stamens into petaloid organs and the replacement of fourth whorl carpels with indeterminate floral meristems, which are similar to ag-2 [8]. Transgenic plants expressing TM29 antisense RNA produced ectopic shoots with partially developed leaves and secondary flowers in the fruit [37]. Here we identified that the inhibition of flower meristem was terminated, and the floral development was reversed into vegetative organs in slf mutants, indicating that SIGT11 activity is required for the function of these previously reported genes.

In Arabidopsis, stem cell maintenance is lost at the stage 6 of floral development, which makes the flower determinate [48]. In WT flowers, WUS mRNA is undetectable at this stage but in $a g$ mutants, WUS is continuously expressed in the FM, resulting in the disrupted FM termination [48]. In slf, SlWUS was not repressed in the later stages of tomato floral development. The direct or indirect repressors of WUS, such as SIKNU, TAG1, SlCLVs, SlULT1, were all down- regulated in slf. However, the floral meristem identity gene $F A$ was upregulated in $s l f$, which was consistent with the defect of floral meristem termination in slf.

Interestingly, AGLF, the homologous gene of SlGT11 in Medicago truncatula, seemed to function only as the $C$ type gene [16]. Despite the similar expression pattern of $A G L F$ and SlGT11 in the inner two whorls, the different developmental defects of stamens and carpels in respective mutants indicate that this gene likely has the different functions in Medicago and tomato. The knockout mutant of the SlGT11 homologous gene in Arabidopsis (At5g51800) showed no defectives in floral organ identity $[16,39]$, indicating that SlGT11 function may have evolutionarily diverged in different species.

In summary, we found that the loss-function of SlGT11 resulted in sepaloid petal at high temperatures in the second whorl, carplloid stamen in the third whorl, and ectopic formation of stem-, leaf- and flower-like structures in the fourth whorl. These phenotypes indicate that SlGT11 has complex functions that are similar to $\mathrm{B} / \mathrm{C} / \mathrm{E}$-class genes in floral organ specification. Spatiotemporal expression analysis showed that SlGT11 was expressed throughout the early stages of the floral development, and SlGT11 expression became more specific to the primordium of stamens and carpels in later stages. Together, our results suggest that SlGT11 functions in floral organ patterning and maintenance of floral determinacy in tomato.

\section{Conclusions}

The results obtained through this study indicate that the disruption of a novel tomato Trihelix gene SlGT11 results in the loss of floral organ identity and the reversion of the flower to vegetative development during the floral development. Together with the spatiotemporal expression pattern of SlGT11, our results suggest that SIGT11 
is essential for the reproductive organ development, but the function of SlGT11 homologous genes is evolutionarily diverged in Arabidopsis and Medicago. The presented study provides new insight into the function of Trihelix gene SIGT11 in the floral development.

\section{Methods}

\section{Plant material and growth conditions}

All plants used in this study were in tomato (Solanum lycopersicum L.) accession Micro-Tom background. Seeds of stamenless like flower (slf) mutant (TOMJPG2637-1) were obtained from the Tomato Mutants Archive (http:// tomatoma.nbrp.jp/). Since the slf mutant is partial sterility, seeds from heterozygous plants were used for generating homozygous individuals.

Seeds were pre-germinated on moistened filter paper at $28^{\circ} \mathrm{C}$ in complete darkness. Plants were grown under long-day conditions (16-h light/8-h dark) in a greenhouse with a relative humidity of $60 \%$. Daytime and nighttime temperatures were $26^{\circ} \mathrm{C}$ and $22^{\circ} \mathrm{C}$, respectively. All plants received regular watering and fertilizer treatments.

\section{Phenotype characterization}

For analyzing the defects of floral organs, we counted the floral organ number of at least 20 flowers on each examined tomato plant. For analyzing the number of stamen in each flower, we collected flowers at anthesis for the quantification. For analyzing the ectopic floral meristem, we removed sepals and petals of examined flowers before anthesis. Immediately after the dissection, morphology of ectopic floral meristem was imaged using Nikon SMZ18 stereomicroscope.

\section{Histological analysis}

To determine morphological and developmental characteristics, fresh floral organs were dissected and examined by Nikon SMZ18 stereomicroscope. The toluidine blue staining was performed as previously described [49]. Briefly the flower buds from the six-week-old WT and slf plants were harvested and treated in FAA (3.7\% formaldehyde, $5 \%$ acetic acid, 50\% ethanol) under vacuum conditions for $30 \mathrm{~min}$. These samples were dehydrated in a graded ethanol and tertbutanol series, and then embedded in a paraffin solution containing $50 \%$ tertbutanol for $4 \mathrm{~h}$. The infiltrated samples were placed in pure paraffin (Sigma-Aldrich) for over-night.

Sections $(10 \mu \mathrm{m}$ thick) were cut with a Leica RM2255 microtome, and the paraffin was further removed by the dewaxing agent. The tissue parts were washed in pure water carefully, and then stained for $1 \mathrm{~min}$ in $0.25 \%$ toluidine blue-O (Sigma-Aldrich, U.S.A). All micrographs were photographed with a Nikon SMZ18 stereomicroscope.

\section{Scanning electron microscopy}

Scanning electron microscopy (SEM) analysis of the flowers at the early stage were conducted as following: the sepals and petals were carefully separated from fresh floral organs under stereomicroscope; these samples were observed using a TM3030 PLUS scanning electronic microscopy under a quanta 250 FEG scanning electron microscope at an accelerating voltage of $5 \mathrm{kV}$.

\section{Subcellular localization}

The 35Spro:SlGT11-GFP and the corresponding empty vector pHellsgate 8 (35Spro:GFP) were transformed into agrobacterium GV3101 and injected into Nicotiana benthamiana leaves. The plants with infiltrated leaves were incubated at $25{ }^{\circ} \mathrm{C}$ in dark for $24 \mathrm{~h}$ and then exposed to light for $12 \mathrm{~h}$ before GFP signals were observed by confocal microscopy (LSM 880, Germany Carl Zeiss). The primers were listed in the S1 Table.

\section{Bulked segregant analysis (BSA)}

Bulked segregant analysis was performed according to Chang et al. [50]. The slf homozygous plants were used as female parent and crossed to the WT. The F1 plants were then selfed to generate F2 mapping population. For BSA-seq, we extracted genomic DNA from 28 slf mutant individuals and $30 \mathrm{WT}$ individuals in the $\mathrm{F}_{2}$ mapping population using CTAB method [51]. All DNA quality and concentration were checked before being mixed to construct two bulks (slf bulk and WT bulk). The slf bulk and WT bulk were sequenced to a depth of $28 \times$ and $30 \times$ coverage of the tomato genome by HiseqXten-PE150 (Novogene). Trimmed sequences are mapped onto the tomato reference genome (Heinz 1706 cultivar) and mutation variants are filtered. Analysis of the allelic variant frequencies in the pools led to the identification of the causal mutation with 100\% frequency in the slf bulk. The genes with the expected allelic frequency of 1 were further examined and we conducted transgenic verification for the identified candidate gene. The candidate genes were cloned and sequenced to verify the mutations. The primers were listed in the S1 Table.

\section{SIGT11 RNAi gene constructs}

To generate the SIGT11 RNA interference transgenic plants, we selected a $253 \mathrm{bp}$-sequence near the $3^{\prime}$ end of the PKc kinase-like domain by Sol Genomics Network vigs tool (https://vigs.solgenomics.net/). The amplified cDNA was cloned into entry vector PDONR221, then further recombined into the binary vector pK7GWIWG2 (II). The binary plasmids were transformed into agrobacterium C58 strain for generating SIGT11 RNAi transgenic lines. 


\section{Plant genetic transformation}

Agrobacterium-mediated transformations of tomato were performed according to Brooks et al. [52]. In brief, cotyledon segments from 6- to 8-d old seedlings were precultured for $1 \mathrm{~d}$ followed by the inoculation with agrobacterium strain C58 containing the RNAi construct. After $2 \mathrm{~d}$ cocultivation, the cotyledon segments were transferred to a selective regeneration medium containing kanamycin. Subcultures were performed every 15 days until these seedlings produced three true leaves. These seedlings were transferred to a selective rooting medium containing kanamycin. Only wellrooted plants were transferred to the greenhouse.

\section{Phylogenetic and sequence analyses}

Sequences of SIGT11 family members in tomato and other species were obtained from the NCBI database (https://blast.ncbi.nlm.nih.gov/Blast.cgi), and aligned using the ClustalW function in MEGA5. Phylogenetic trees for proteins with 1000 bootstrap replicates were constructed using the maximum likelihood method in MEGA5.

\section{Imaging, microscopy and GUS staining}

To produce the pSIGT11::GUS construct, $3 \mathrm{~kb}$ of genomic sequence comprising the SIGT11 upstream region, was cloned into PGWB432 binary vector by the infusion cloning method. Whole floral primordium and flowers at different stages were stained with GUS solution in $37^{\circ} \mathrm{C}$ for $10 \mathrm{~h}$ after the fixation in cold $90 \%$ acetone for $20 \mathrm{~min}$. These samples were dehydrated in a solution (ethanol: acetic acid glacial, in proportions $4: 1$ by volume) for about $6 \mathrm{~h}$ [53]. The samples were then cleared and washed briefly by different concentration ethanol (40\% ethanol for $15 \mathrm{~min}, 20 \%$ ethanol for $15 \mathrm{~min}, 10 \%$ ethanol for $15 \mathrm{~min}$ ). The dehydrated samples were embedded in 5\% agar and sectioned by Vibrating slicer (Leica, Germany). The expression pattern of SIGT11 was observed by a Nikon SMZ18 stereomicroscope [54].

\section{Quantitative real-time PCR analysis}

For quantitative real time PCR (qRT-PCR), four-weekolds tomato plants with similar growth conditions were used for tissue collection including roots, hypocotyls, cotyledons, stems, leaves, flowers, fruits, different floral organs and the flowers at different developmental stages [41]. Total RNA was isolated using the Eastep Super Total RNA Extraction Kit (Promega, Shanghai). Subsequently, HIScript II 1st Strand cDNA Synthesis Kit (+gDNA wiper, Vazyme) was used to synthesize the first strand cDNA. ChamQ Universal SYBR qPCR Master Mix kit (Vazyme) was used to perform qRT-PCR reactions in a 7300 Real-Time PCR System (CFX Connect, BIO-RAD). An actin gene was used as the constitutive control. The relative gene expressions were calculated using the $2^{\text {inu- }-\Delta \Delta \text { ct }}$ method [50]. All analyses were performed in three biological replicates and two technical replicates. All primer sequences for qRT-PCR can be found in Table S1.

\section{Yeast-one-hybrid assay}

Yeast-one-hybrid assay was performed using the Matchmaker EYG48 Yeast-one-hybrid system (Clontech) as described by the manual. The coding sequence of SIGT11 for effector protein was cloned into the PJG4-5 vector, and the promoter sequence of $\mathrm{B} / \mathrm{C} / \mathrm{E}$ class genes were cloned into the reporter vector Placzy. Both vectors were transformed into the EYG48 yeast strain. Diploid yeast cells were grown and selected on dropout medium without uracil and tryptophan. To assay proteinpromoter interactions, clones were grown on twodropout medium without uracil and tryptophan, but with $\mathrm{x}$-gal, for $2 \mathrm{~d}$ at $30^{\circ} \mathrm{C}$. The empty vectors were used as control. All primer sequences used for cloning can be found in Table S1.

\section{Yeast-two-hybrid assay}

Protein interaction assays in yeast were performed using the Matchmaker Gold Yeast Two-Hybrid System (Clontech) according to the manual. The SlGT11 coding sequence for bait protein was cloned into the pGBKT7 vector and $B C E$ class genes for prey proteins were cloned into the pGADT7 vector. The vectors were then transformed into the Y2HGold yeast strain. Diploid yeast cells were selected and grown on dropout medium without leucine and tryptophan. To assay protein-protein interactions, clones were grown on quadruple-dropout medium without leucine, tryptophan, histidine and adenine for $3 \mathrm{~d}$ at $30^{\circ} \mathrm{C}$. All primer sequences used for cloning can be found in Table S1.

\section{Supplementary Information}

The online version contains supplementary material available at https://doi. org/10.1186/s12870-020-02760-2.

\section{Additional file 1: Figure S1. Phenotype of ovary and}

fruit in WT and slf.

Additional file 2: Figure S2. Phylogenetic analysis of S/GT11 and its homologs.

Additional file 3: Figure S3. Multiple alignment of SIGT11 and its homologs.

Additional file 4: Figure S4. Yeast two-hybrid assays.

Additional file 5: Figure S5. Yeast one-hybrid assays.

Additional file 6: Table S1. PCR primer sequences used in this study.

Acknowledgements

We thank Bing Hua for critical reading of this manuscript. We are grateful to the Tomato Mutants Archive for supplying the tomato seeds of the slf mutants. 


\section{Authors' contributions}

S.W., S.Q. and X. L designed the research; L.Y. performed the experiments; L.Y., S.Q., H.L. and S.W. analyzed the data; L.Y., A.T., X. Z, X. L and S.W. wrote the paper. All authors have read and approved the manuscript.

\section{Funding}

This study was supported by The National Key Research and Development Program of China (2018YFD1000800), the National Natural Science Foundation of China (31722006) and Key Research Program of Fujian Province (2018NZO002). The funding bodies played no role in the design of the study and collection, analysis, and interpretation of data and in writing the manuscript.

\section{Availability of data and materials}

All data generated or analyzed during this study are included in this published article and its supplementary information files. The datasets used and analyzed during the current study are available from the corresponding author on reasonable request.

\section{Ethics approval and consent to participate}

Not applicable.

\section{Consent for publication}

Not applicable.

\section{Competing interests}

The authors declare no competing financial interests.

\section{Received: 3 April 2020 Accepted: 1 December 2020} Published online: 14 December 2020

\section{References}

1. Enrico CS, Meyerowitz EM. The war of the whorls: genetic interactions controlling flower development. Nature. 1991;353:31-7.

2. Theissen G. Development of floral organ identity: stories from the MADS house. Curr Opin Plant Biol. 2001;4:75-85.

3. Theißen G, Saedler H. Floral quartets. Nature. 2001:409:469-71.

4. Colombo L, Franken J, Koetje E, van Went J, Dons HJM, Angenent GC, van Tunen AJ. The petunia MADS box gene FBP11 determines ovule identity. Plant Cell. 1995;7:1859-68.

5. Dennis L, Peacock J. Genes directing flower development in Arabidopsis. Plant Cell. 2019:31:1192-3.

6. de Martino G, Pan I, Emmanuel E, Levy A, Irish VF. Functional analyses of two tomato APETALA3 genes demonstrate diversification in their roles in regulating floral development. Plant Cell. 2006;18:1833-45.

7. Geuten K, Irish V. Hidden variability of floral homeotic B genes in Solanaceae provides a molecular basis for the evolution of novel functions. Plant Cell. 2010;22:2562-78.

8. Pnueli L, Hareven D, Rounsley SD, Yanofsky MF, Lifschitz E. Isolation of the tomato AGAMOUS gene TAG1 and analysis of its homeotic role in transgenic plants. Plant Cell. 1994;6:163-73.

9. Gimenez E, Eda LC, Pineda B, Pan IL, Moreno V, Angosto T, Lozano R. TOMATO AGAMOUS1 and ARLEQUIN/TOMATO AGAMOUSLIKE1 MADS-box genes have redundant and divergent functions required for tomato reproductive development. Plant Mol Biol. 2016:91:513-31.

10. Soyk S, Lemmon ZH, Oved M, Fisher J, Liberatore KL, Park SJ, Goren A, Jiang K, Ramos A, van der Knaap E, et al. Bypassing negative epistasis on yield in tomato imposed by a domestication gene. Cell. 2017;169(6):1142-55.

11. Gomez P, Jamilena M, Capel J, Zurita S, Angosto T, Lozano R. Stamenless, a tomato mutant with homeotic conversions in petals and stamens. Planta. 1999;209:172-9.

12. Quinet M, Bataille G, Dobrev PI, Capel C, Gómez P, Capel J, Lutts S, Motyka $\checkmark$, Angosto T, Lozano R. Transcriptional and hormonal regulation of petal and stamen development by STAMENLESS, the tomato (Solanum lycopersicum L.) orthologue to the B-class APETALA3 gene. J Exp Bot. 2014; 65:2243-56.

13. Cao X, Liu X, Wang X, Yang M, van Giang T, Wang J, Liu X, Sun S, Wei K, Wang $X$, et al. B-class MADS-box TM6 is a candidate gene for tomato male sterile-1526. Thero Appl Genet. 2019;132:2125-35.

14. Trobner W, Ramirez L, Motte P, Hue I, Huijser P, Lonnig WE, Saedler $H$ Sommer H, Schwarz-Sommer Z. GLOBOSA: a homeotic gene which interacts with DEFICIENS in the control of Antirrhinum floral organogenesis. EMBO J. 1992;11:4693-704.

15. Xiao H, Tang J, Li Y, Wang W, Li X, Jin L, Xie R, Luo H, Zhao X, Meng Z, et al. STAMENLESS 1 , encoding a single $\mathrm{C} 2 \mathrm{H} 2$ zinc finger protein, regulates floral organ identity in rice. Plant J. 2009;59:789-801.

16. Zhao Y, Liu R, Xu Y, Wang M, Zhang J, Bai M, Han C, Xiang F, Wang Z Mysore KS, et al. AGLF provides C-function in floral organ identity through transcriptional regulation of AGAMOUS in Medicago truncatula. Proc Natl Acad Sci. 2019:116:5176-81.

17. Xu Y, Gan E, Yamaguchi N, Toshiro I. When to stop: an update on molecular mechanisms of floral meristem termination. J Exp Bot. 2019:70:1711-8.

18. Fletche JC, Brand U, Unnin MP, Simon R, Meyerowitz EM. Signaling of cell fate decisions by CLAVATA3 in Arabidopsis shoot meristems. Science. 1999: 283:1911-4

19. Yadav RK, Perales M, Gruel JRM, Girke T, Nsson HJ, Reddy GV. WUSCHEL protein movement mediates stem cell homeostasis in the Arabidopsis shoot apex. Development Genes. 2011;25:2025-30.

20. Yanofsky MF, HMJL. The protein encoded by the Arabidopsis homeotic gene AGAMOUS resembles transcription factors. Nature. 1990:346:35-9.

21. Lenhard M, Bohnert $A$, Jürgens $G$, Laux $T$. Termination of stem cell maintenance in Arabidopsis floral meristems by interactions between WUSCHEL and AGAMOUS. Cel. 2001;105:805-14.

22. Lohmann JU, Hong RL, Hobe M, Busch MA, Parcy F, Simon R, Weigel D. A molecular link between stem cell regulation and floral patterning in Arabidopsis. Cell. 2001;105:793-803.

23. Sun $B, X u Y, N g ~ K$, Ito T. A timing mechanism for stem cell maintenance and differentiation in the Arabidopsis floral meristem. Gene Dve. 2009;23: $1791-804$.

24. Carles CC, Choffnes-Inada D, Reville K, Lertpiriyapong K, Fletcher JC. ULTRAPETALA1 encodes a SAND domain putative transcriptional regulator that controls shoot and floral meristem activity in Arabidopsis. Development. 2005:132:897-911.

25. Fletcher JC. The ULTRAPETALA gene controls shoot and floral meristem size in Arabidopsis. Development. 2001;128:1323-33.

26. Carles CC, Fletcher JC. The SAND domain protein ULTRAPETALA1 acts as a trithorax group factor to regulate cell fate in plants. Genes Dev. 2009;23: 2723-8

27. Prunet NL, Morel P, Thierry A, Yuval Eshed BJLB, Negrutiu I, Trehin C. REBELOTE, SQUINT, and ULTRAPETALA1 function redundantly in the temporal regulation of floral meristem termination in Arabidopsis thaliana. Plant Cell. 2008:20:901-19.

28. Maier AT, Stehling-Sun S, Wollmann H, Demar M, Hong RL, Haubeiss S, Weigel D, Lohmann JU. Dual roles of the bZIP transcription factor PERIAN THIA in the control of floral architecture and homeotic gene expression. Development. 2009:136:1613-20.

29. Zhang K, Wang R, Zi H, Li Y, Cao X, Li D, Guo L, Tong J, Pan Y, Jiao Y, et al. AUXIN RESPONSE FACTOR3 regulates floral meristem determinacy by repressing cytokinin biosynthesis and signaling. Plant Cell. 2018;30:324-46.

30. Bollier N, Sicard A, Leblond J, Latrasse D, Gonzalez N, Gévaudant F, Benhamed M, Raynaud C, Lenhard M, Chevalier C, et al. At-MINI ZINC FING ER2 and SI-INHIBITOR OF MERISTEM ACTIVITY, a conserved missing link in the regulation of floral meristem termination in Arabidopsis and tomato. Plant Cell. 2018:30:83-100.

31. Tooke F, Ordidge M, Chiurugwi T, Battey N. Mechanisms and function of flower and inflorescence reversion. J Exp Bot. 2005;56:2587-99.

32. Okamuro JK, den Boer BGW, Lotys-Prass C, Szeto W, Jofuku KD. Flowers into shoots: photo and hormonal control of a meristem identity switch in Arabidopsis. Proc Natl Acad Sci. 1996;93:13831-6.

33. Asbe A, Matsushita SC, Gordon S, Kirkpatrick HE, Madlung A. Floral reversion in Arabidopsis suecica is correlated with the onset of flowering and meristem transitioning. PLoS One. 2015;10:e127897.

34. McCullough E, Wright KM, Alvarez A, Clark CP, Rickoll WL, Madlung A. Photoperiod-dependent floral reversion in the natural allopolyploid Arabidopsis suecica. New Phytol. 2010;186:239-50.

35. Ordidge $M$, Chiurugwi T, Tooke F, Battey NH. LEAFY, TERMINAL FLOWER1 and AGAMOUS are functionally conserved but do not regulate terminal flowering and floral determinacy in Impatiens balsamina. Plant J. 2005;44: 985-1000.

36. Angenent GC, Franken J, Busscher M, Weiss D, van Tunen AJ. Cosuppression of the petunia homeotic gene fop2 affects the identity of the generative meristem. Plant J. 1994;5:33-44. 
37. Ampomah-Dwamena C, Morris BA, Sutherland P, Veit B, Yao J. Downregulation of TM29, a tomato SEPALLATA homolog, causes parthenocarpic fruit development and floral reversion. Plant Physiol. 2002;130(2):605-17.

38. Yu C, Cai X, Ye Z, Li H. Genome-wide identification and expression profiling analysis of trihelix gene family in tomato. Biochem Bioph Res Co. 2015;468: 653-9.

39. Zhu B, Li H, Hou Y, Zhang P, Xia X, Wang N, Wang H, Mysore KS, Wen J, Pei $Y$, et al. AGAMOUS AND TERMINAL FLOWER controls floral organ identity and inflorescence development in Medicago truncatula. J Integr Plant Biol. 2019; 61:917-23.

40. Saito T, Ariizumi T, Okabe Y, Asamizu E, Hiwasa-Tanase K, Fukuda N, Mizoguchi T, Yamazaki Y, Aoki K, Ezura H. TOMATOMA: a novel tomato mutant database distributing micro-tom mutant collections. Plant Cell Physiol. 2011;52:283-96.

41. Brukhin V, Hernould M, Gonzalez N, Chevalier C, Mouras A. Flower development schedule in tomato Lycopersicon esculentum cv. Sweet cherry. Sex Plant Reprod. 2003;15:311-20.

42. Polowick PL, Bolaria R, Sawhney VK. Stamen ontogeny in the temperaturesensitive 'stamenless-2' mutant of tomato (Lycopersicon esculentum L.). New Phytol. 1990;115:625-31.

43. Alvarez-Buylla ER, Benítez M, Corvera-Poiré A, Chaos Cador Á, de Folter S, Gamboa De Buen A, Garay-Arroyo A, García-Ponce B, Jaimes-Miranda F, Pérez-Ruiz RV, et al. Flower development. Arabidopsis Book. 2010;8:e127.

44. Pucci A, Picarella ME, Mazzucato A. Phenotypic, genetic and molecular characterization of $7 B-1$, a conditional male-sterile mutant in tomato. Theor Appl Genet. 2017:130:2361-74.

45. Guo X, Hu Z, Yin W, Yu X, Zhu Z, Zhang J, Chen G. The tomato floral homeotic protein FBP1-like gene, S/GLO1, plays key roles in petal and stamen development. Sci Rep-UK. 2016;6:20454.

46. Itkin M, Seybold H, Breite D, Rogachev I, Meir S, Aharoni A. TOMATO AGAMOUS-LIKE 1 is a component of the fruit ripening regulatory network. Plant J. 2009;60:1081-95.

47. Sieburth LE, Running MP, Meyerowitz EM. Genetic separation of third and fourth whorl functions of AGAMOUS. Plant Cell. 1995;7:1249-58.

48. Sun B, Looi L, Guo S, He Z, Gan E, Huang J, Xu Y, Wee W, Ito T. Timing mechanism dependent on cell division is invoked by polycomb eviction in plant stem cells. Science. 2014:343:498-9.

49. Carrera E, Ruiz-Rivero O, Peres LEP, Atares A, Garcia-Martinez JL. Characterization of the procera tomato mutant shows novel functions of the SIDELLA protein in the control of flower morphology, cell division and expansion, and the auxin-signaling pathway during fruit-set and development. Plant Physiol. 2012;160:1581-96.

50. Chang J, XulD Z, Li M, Yang M, Qin H, Yang J, Wu S. Spatiotemporal cytoskeleton organizations determine morphogenesis of multicellular. PLoS Genet. 2019;10:e1008438.

51. Porebski S, Bailey LG, Baum BR. Modification of a CTAB DNA extraction protocol for plants containing high polysaccharide and polyphenol components. Plant Mol Biol Report. 1997:15:8-15.

52. Brooks C, Nekrasov V, Lippman ZB, Van Eck J. Efficient gene editing in tomato in the first generation using the clustered regularly interspaced short palindromic repeats/CRISPR-associated9 system1. Plant Physiol. 2014; 166:1292-7.

53. Xu M, Chen F, Qi S, Zhang L, Wu S. Loss or duplication of key regulatory genes coincides with environmental adaptation of the stomatal complex in Nymphaea colorata and Kalanchoe laxiflora. Hortic Res. 2018;5:42-58.

54. Lee DK, Geisler M, Springer PS. LATERAL ORGAN FUSION1 and LATERAL ORGAN FUSION2 function in lateral organ separation and axillary meristem formation in Arabidopsis. Development. 2009;136:2423-32.

\section{Publisher's Note}

Springer Nature remains neutral with regard to jurisdictional claims in published maps and institutional affiliations.

\section{Ready to submit your research? Choose BMC and benefit from:}

- fast, convenient online submission

- thorough peer review by experienced researchers in your field

- rapid publication on acceptance

- support for research data, including large and complex data types

- gold Open Access which fosters wider collaboration and increased citations

- maximum visibility for your research: over $100 \mathrm{M}$ website views per year

At BMC, research is always in progress.

Learn more biomedcentral.com/submissions 